SKIN EFFECT OF Hf-RICH MELTS AND SOME ASPECTS IN ITS

IUSAGE FOR HF-CONTAINING CAST NICKEL-BASE SUPERALLOYS

Zheng Yunrong and Li Chenggong

Institute of Aeronautical Materials, Beijing, China

\begin{abstract}
Hf-rich melts have a skin effect when Hf-containing cast nickel-base superalloys melt or solidify at temperature range $1250-1290^{\circ} \mathrm{C}$. In this interval the interdendritic liquid maintains perfect interconnection and can overflow to surface. It has been proved that Hf content in skin liquid is four times more than its average content in the alloy. The liquid has superior fluidity and wettability, therefore it has a capability of self brazing and a recovery effect on cracks. Using Hf-rich melts as a brazing material has successfully brazed cast superalloy. By means of diffusion treatment, residual $\mathrm{Ni}_{5} \mathrm{Hf}$ in lapping zone transforms into secondary $\mathrm{MC}_{(2)}$. As a result, in lapping zone a reasonable structure like Mar-M200+Hf was obtained. High chemical activity of the skin liquid is a disadvantage. At the surface where the skin liquid contacts shell mold, a thin layer of $\mathrm{HfO}_{2}$ can form.
\end{abstract}


Today, Hf-containing cast nickel-base superalloys have been used for blade material of advanced gas turbines. Many papers concerning the effect of Hf on superalloys were published. Early works were focused on microstructure and mechanical properties (1) (2). Recently. metallurgists pay more attention to the effect of $\mathrm{Hf}$ in solidification field and determine the distribution and segregation of Hf during solidification of superalloys (3) (4).

Our works have shown that Hf widens the solidification range of superalloy, but it can narrow down the range between temperature lost the interdendritic capillary feeding and solidus, as well as can decrease the liquid volume percent nesessary for linking the interdendritic pools in the late solidification, therefore can cause beneficial effect on castability and weldability of alloy(5). In this paper, we will explore some characteristics of Hf-rich melts during solidification and melting.

\section{Materials and Procedures}

Chemical composition of testing materials is listed in Table I.

Table I. Chemical Composition of Alloys, wt.-\%

\begin{tabular}{rrrrrrrrrrrrrr}
\hline Alloy & Co & Cr & $W$ & Mo & Nb & Al & Ti & Hf & Zr & $C$ & B & Ni \\
\hline K5 & 9.85 & 9.53 & 4.82 & 3.80 & -- & 5.65 & 2.40 & -- & 0.083 & 0.14 & 0.023 & base \\
K5H & 9.58 & 9.36 & 4.74 & 3.74 & -- & 5.73 & 2.32 & 1.41 & 0.115 & 0.13 & 0.023 & base \\
K3H & 4.99 & 10.41 & 4.87 & 3.96 & -- & 6.14 & 2.72 & 5.62 & -- & 0.13 & 0.016 & base \\
K19H & 11.95 & 5.65 & 10.15 & 1.95 & 2.42 & 5.28 & 1.26 & 1.27 & 0.045 & 0.10 & 0.08 & base \\
DZ22 & 9.93 & 8.61 & 12.55 & -- & 1.06 & 5.21 & 1.98 & 1.96 & 0.078 & 0.14 & 0.016 & base
\end{tabular}

Specimens of $\mathrm{K} 5 \mathrm{H}$ superalloy for isothermal solidification were heated to $1370^{\circ} \mathrm{C}$, soaked for 15 minutes, then cooled to different solidified temperature and quenched into water after 5 minutes isothermal duration. Some specimens were directionally solidified into dendritic structure and then quenched.

The plates of alloy $\mathrm{K} 5 \mathrm{H}$ with $5 \mathrm{~mm}$ thickness were polished by metallography and then melted by tungsten inert gas(TIG) welding in order to observe the Hf-rich liquid film in molten and heat-affected zone.

Alloy $\mathrm{K} 19 \mathrm{H}$ was put into a vacuum furnace and heated to $1260-1270^{\circ} \mathrm{C}$. Collecting incipient melting drops and solidifying it, we analyzed microstructure of the button ingot.

The morphology and structure of ingot surface touching shell mold was determined by SEM, EDAX, EPMA and X-ray diffraction.

Using $\mathrm{Hf}-\mathrm{rich}$ skin melts brazed Hf-free $\mathrm{K} 3 \mathrm{H}$ and then lapped specimens experienced diffusion treatment to remove residual Ni5Hf phase.

Experimental Results

Change of Hf Concentration During Solidification

Onset formation of $\gamma$ dendrite takes place at $1350^{\circ} \mathrm{C}$. for alloy $\mathrm{K} 5 \mathrm{H}$. As temperature decreases, dendrite grows very rapidly and dendritic skeleton basically forms at $1310^{\circ} \mathrm{C} .7 \mathrm{vol} \%$ liquid still exists in the interior of 
alloy and the melts at the interdendrite remain interconnected at $1250^{\circ} \mathrm{C}$. There is still 0.5 vol. $\%$ liquid below $1180^{\circ} \mathrm{C}$. This part of liquid does not completely solidify until $\mathrm{Ni}_{5} \mathrm{Hf}$ forms at $1130^{\circ} \mathrm{C}$.

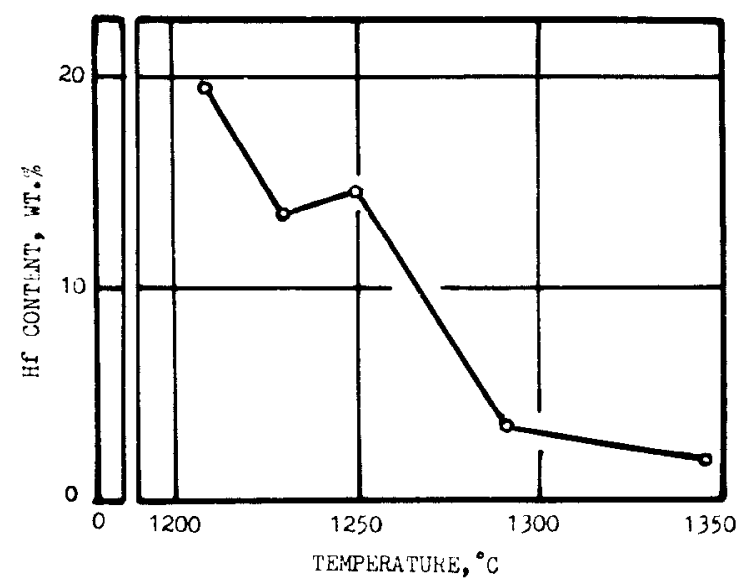

Figure 1 -- Relationship between Hf content of melts and temperature of isothermal solidification for alloy $\mathrm{K} 5 \mathrm{H}$.

Change of Hf concentration in the liquid is very obvious during solidification. The results were given in Fig.1. It can be seen that below $1290^{\circ} \mathrm{C}$ Hf content in interdentritic liquid increases rapidly, but from 1250 to $1230^{\circ} \mathrm{C}$ Hf concentration in molten pools decreases slightly. This is relative to precipitation of Hf-rich $M C(2)$ carbide within the temperalure inlerval.

Skin Effect of Hf-Rich Melts

A thin Hf-rich layer can be observed near the weld bead and heat-affected zone when plates of alloy $\mathrm{K} 5 \mathrm{H}$ are melted by TIG. HE content in this layer is four times more than its average content in the alloy. At solidified surface a river pattern caused by overflowing and spreading of Hf-rich melts along interdendritic capillary can be observed, Fig.2a. Metallographic analysis revealed a typical eutectic structure of $\mathrm{Ni}-\mathrm{Hf}$ in river zone, Fig.2b.

Skin liquid film was analyzed by EPMA and its composition was compared with that of dendrite and interdendrite, as shown in Table II. As we know from the Table, the composition of liquid film is closer to that of interdendrite. This indicates that the 1 iquid film is to overflow to surface during the late period of solidification. Fig.3 shows the profile of Hf.

Table II. Composition of Skin Melts in Alloy KJH, wt.\%

\begin{tabular}{llllllllll}
\hline Location & Cr & Al & Ni & Ti & Mo & W & Hf & Co \\
& & & & & & & & \\
\hline Skin melt & 9.04 & 4.64 & 58.45 & 3.93 & 3.85 & 4.89 & 6.55 & 8.84 \\
Interdendrite & 9.83 & 5.18 & 62.22 & 3.38 & 4.29 & 3.39 & 3.06 & 8.65 \\
Dendrite & 9.37 & 5.09 & 64.50 & 1.90 & 3.59 & 5.84 & 0.00 & 9.71
\end{tabular}

A dark copper-color layer was found at the surface of internal shrinkage cavity of Hf-containing ingots and its content of Hf was identified as 3 to $7 \mathrm{wt} . \%$ by EPMA. This is another important evidence for skin effect of Hf. 


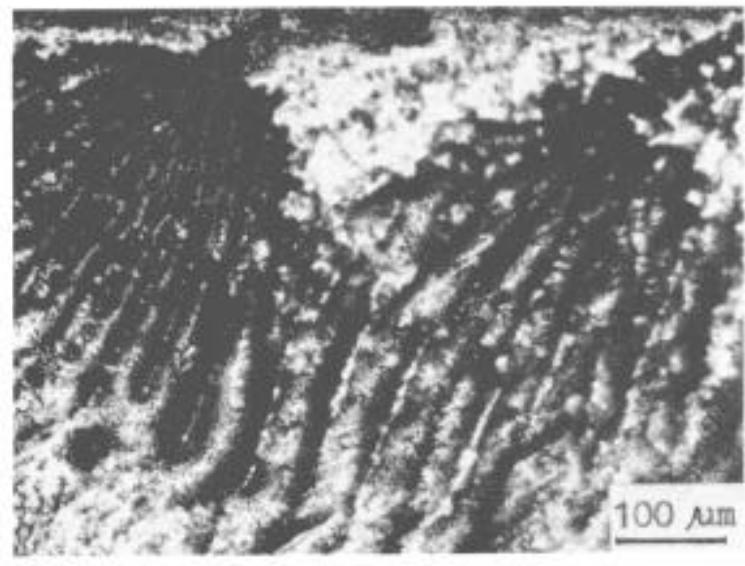

a)

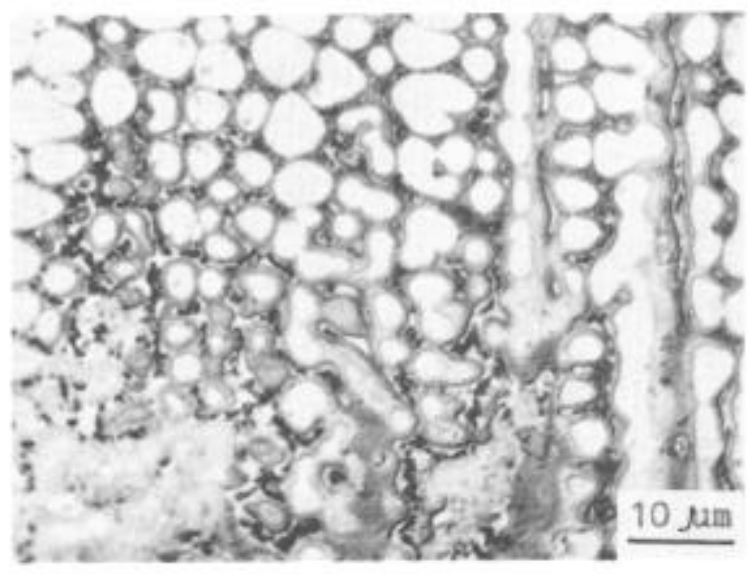

b)

Figure 2 -- Flowing trace of Hf-rich melts at weld bead surface for $\mathrm{K} 5 \mathrm{H}$, a) river pattern and b) $\mathrm{Ni}-\mathrm{Hf}$ eutectic at river zone.

In heat affected zone the melting point of interdendrite is $160^{\circ} \mathrm{C}$ lower than that of dendrite. Hf-rich liquid $\mathrm{film}$ appears earlier than liquid spherule which means heavy melting. The film and spherule can be observed under $\mathrm{SEM}$, as shown in Fig. 4 .

It can be noticed that Hf-rich melts spread on surface and then form liquid drops when alloy $\mathrm{K} 19 \mathrm{H}$ is put into a vacuum furnace and heated to 1260 $-1270^{\circ} \mathrm{C}$. After collecting the drop and solidifying it, a typical eutectic structure consisted of eutectic $\gamma^{\prime}$, Nis $\mathrm{Hf}, \mathrm{M}_{3} \mathrm{~B}_{2}, \mathrm{MC}$ and $\gamma$ was found in the button ingot, Fig.5. Quantitative metallographic analysis has show that the volume percent of $\mathrm{Ni}_{5} \mathrm{Hf}$ is $1.2 \%$ in alloy, but $8.1 \%$ in microingot. EDAX result has proved that average content of Hf in drop is three times as high as that in alloy.

Influence of Skin Effect on Weld Cracking

Alloy $\mathrm{K} 5$ and $\mathrm{K} 5 \mathrm{H}$ were welded by TIG without filler. Crack length $\mathrm{L}$ and numbers $N$ per unit area in both molten and heat affected zone were measured by quantitative metallography. The results are given in Table III. L and N in $\mathrm{Hf}-\mathrm{free}$ superalloy are a magnitude order higher than ones in $\mathrm{Hf}$-containing alloy. Using Hf-rich melts as a filler of weld can also decrease weld cracking.

Hf decreases tendency to weld cracking, because Hf-containing alloy has perfect connection of interdendrite and skin liquid film has a self recovery effct on formed cracks. There are a lot of distinct cracks in HAZ for alloy K5 (Fig.6a), but some cracks are welded by Hf-rich liquid, only residual mark of crack remains for $\mathrm{K} 5 \mathrm{H}$ (Fig.6b).

Application of Hf-Rich Melts to Brazing

$\mathrm{Ni}_{5} \mathrm{Hf}$ phase melts at $1160^{\circ} \mathrm{C}$ for Hf-containing superalloy and the Hf-rich melts formed have superior fluidity and wettability. As metioned above, skin liquid mainly contains $\mathrm{Ni}$ and $\mathrm{Hf}$. We prepared a series of alloys in which content of Hf is more than 10 percent. Fig. 7 shows the microstructure of a typical alloy and it is similar to Fig.2b. Hf-free K3H alloy was brazed by 


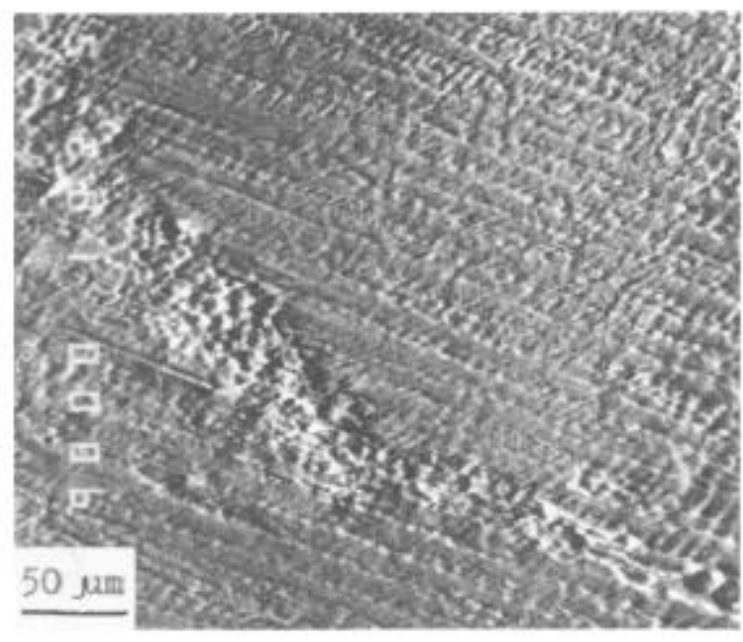

a)

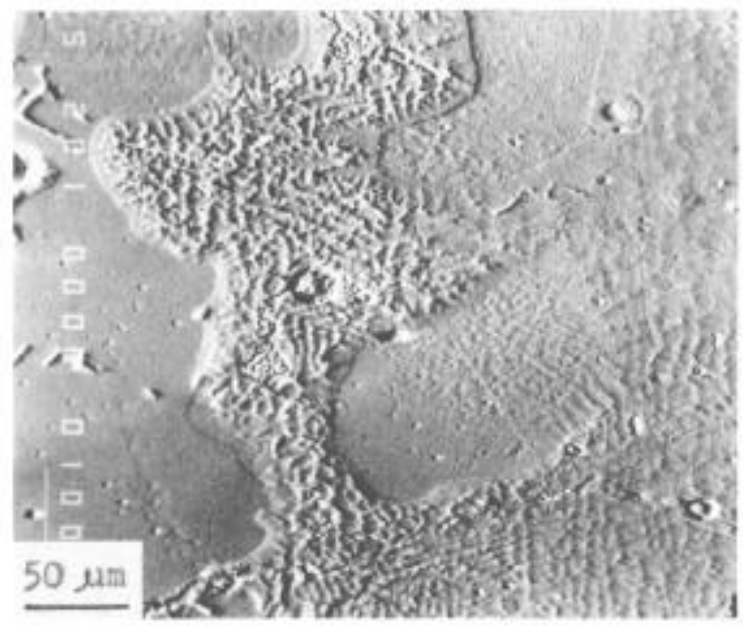

c)

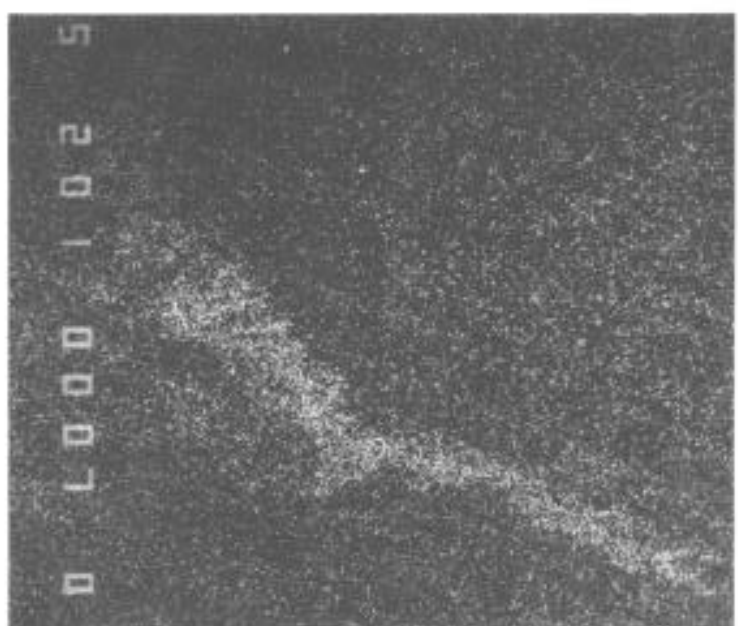

b)

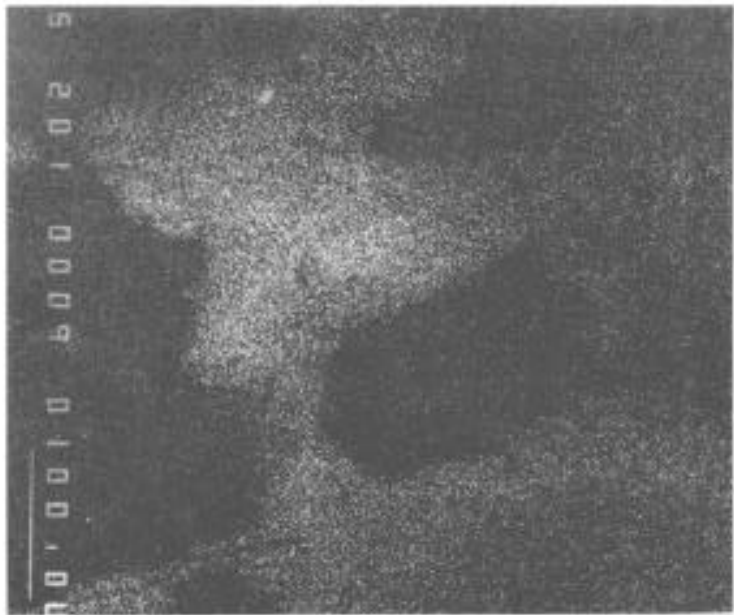

d)

Figure 3 -- Distribution of Hf, a), b) surface of weld bead and c), d) HAZ for alloy $\mathrm{K} 5 \mathrm{H}$.

Table III. Comparison of Sensitivity to Weld Cracking

\begin{tabular}{lllll}
\hline Alloy & \multicolumn{2}{c}{ Weld bead zone } & HAZ \\
& $\mathrm{L}\left(\mathrm{mm} / \mathrm{mm}^{2}\right)$ & $\mathrm{N}\left(\right.$ number $\left./ \mathrm{mm}^{2}\right)$ & $\mathrm{L}\left(\mathrm{mm} / \mathrm{mm}^{2}\right)$ & $\mathrm{N}\left(\mathrm{number} / \mathrm{mm}^{2}\right)$ \\
$\mathrm{K5} 5$ & 0.20 & 0.17 & 0.20 & 0.54 \\
$\mathrm{~K} 5 \mathrm{H}$ & 0.018 & 0.02 & 0.025 & 0.057 \\
\hline
\end{tabular}

this material under vacuum. In weld condition $\mathrm{Ni}_{5} \mathrm{Hf}$ still exists in lapping zone. Microstructure in this region is similar to incipient melting structure of Hf-containing alloy, Fig. 8 .

Hf is a strong former of $\gamma^{\prime}$ and MC carbide. It can easily resolve into

$\gamma^{\prime}$ and form $\mathrm{Hf}-\mathrm{rich}$ secondary $\mathrm{MC}_{(2)}$ by the reaction of $\mathrm{Ni}_{5} \mathrm{Hf}+\gamma(\mathrm{C}) \rightarrow$

$\mathrm{MC}_{(2)}+\gamma$. After diffusion treatment, $\mathrm{Ni}{ }_{5} \mathrm{Hf}$ can be eliminated and reasonable 


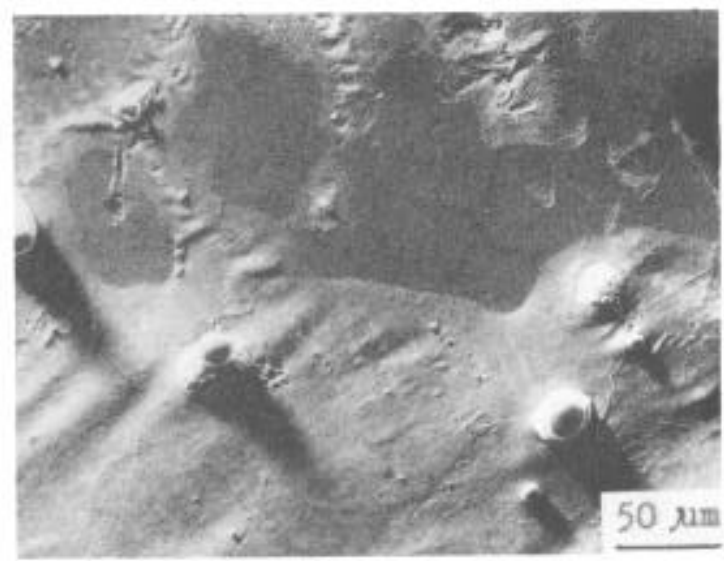

Figure 4 -- Liquid film and spherule of alloy Dz22.

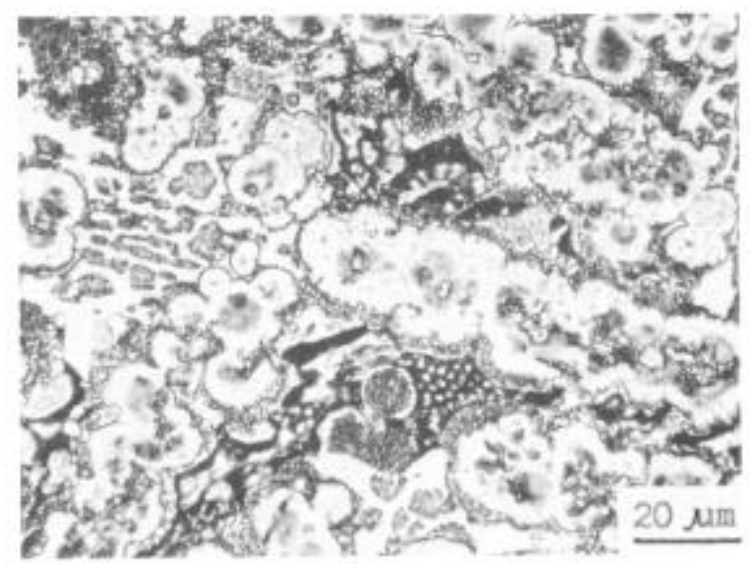

Figure 5 -- Microstructure of skin liquid button ingot of alloy $\mathrm{K} 19 \mathrm{H}$.

lapping structure can be obtained, Fig.9. It is noticed that there is no $\mathrm{Ni}_{5} \mathrm{Hf}$, but there are a lot of eutectic $\nu+\nu^{\prime}$ and block $\mathrm{MC}_{(2)}$ in lapping zone. This kind of microstructure is familiar to us in Mar-M200+Hf alloy.

As compared to $\mathrm{Ni}-\mathrm{Cr}-\mathrm{Si}-\mathrm{B}$, Hf-rich brazing material has no brittleness, because NisHf phase is not brittle. Vicker hardness of the phase is $480 \mathrm{~kg} / \mathrm{mm}^{2}$ and much lower than ones of boride and silicide. On the other hand, Si is considered as a impurity element, but Hf is a beneficial one in superalloys. Hf diffused into $\gamma^{\prime}$ ' will strengthen it further.

\section{Formation of $\mathrm{HfO}_{2}$}

In Hf-containing investment castings, it is not in the early, but in the late solidification to form $\mathrm{HfO}_{2}$ most easily. In the late solidification, skin liquid can react with shell mold and form a layer of $\mathrm{HfO}_{2}$.

HfO2 often grows as small dendrites at surface of castings. A continuous layer of $\mathrm{HfO}_{2}$ was revealed after slight polishing, Fig.10a. The microphotograph is not clear due to bad electrical conductivity of oxide. Evaparating gold on oxide makes dendrites of $\mathrm{HfO}_{2}$ more destinct, Fig.10b. A large area polished in Fig.10a was analyzed by EDAX and the result was illustracted in Fig.11. X-ray diffraction has proved that $\mathrm{HfO}_{2}$ exists at the surface of castings for alloy K3H, K5H and D222. Fig.12 shows X-ray diffraction diagram of $\mathrm{HfO}_{2}$ for $\mathrm{K} 3 \mathrm{H}$. It is obvious that oxide layer consists of pure $\mathrm{HfO}_{2}$.

SEM and EPMA experiments have demostrated that $\mathrm{HfO}_{2}$ appears as grained shape when Hf content in alloy is less than $1.0 \mathrm{wt} . \%$, but as Hf content in alloy increases to $2.0 \mathrm{wt} \%$, a continuous layer of $\mathrm{HfO}_{2}$ forms. The compositions are same in both grained and continuous $\mathrm{HfO}_{2}$. Hf content of $\mathrm{HfO}_{2}$ is as high as 80wt.\%; concentration of oxygen is about $12 \mathrm{wt} . \%$; $\mathrm{Ni}$, Co and Ti contents are $3.38,0.66$ and $3.53 \mathrm{wt} . \%$ respectively and the amounts of other elements are very low. The characteristic of its composition corresponds to the result of Fig.11.

It is found that the scale of $\mathrm{HfO}_{2}$ is discontinuous for alloy $\mathrm{K5H}$ with 1.7 wt.\% Hf. Surface area in which $\mathrm{HfO}_{2}$ exists exactly matches the spreading 


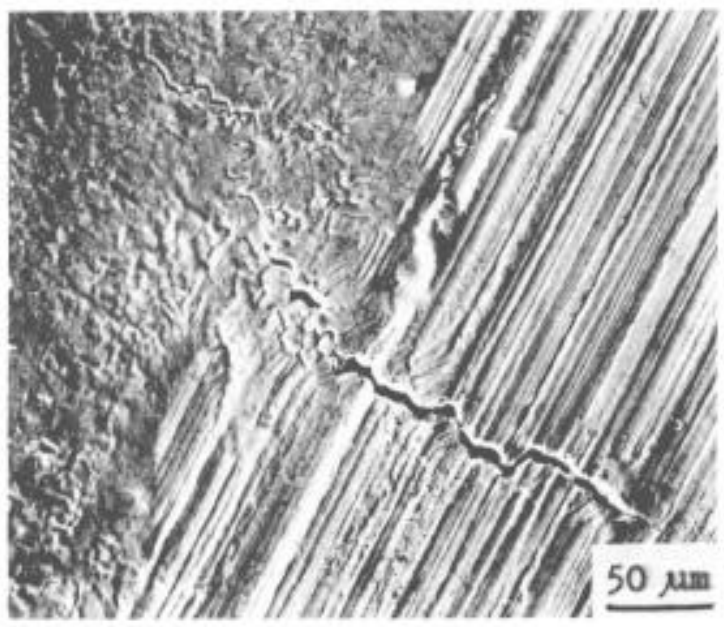

a)

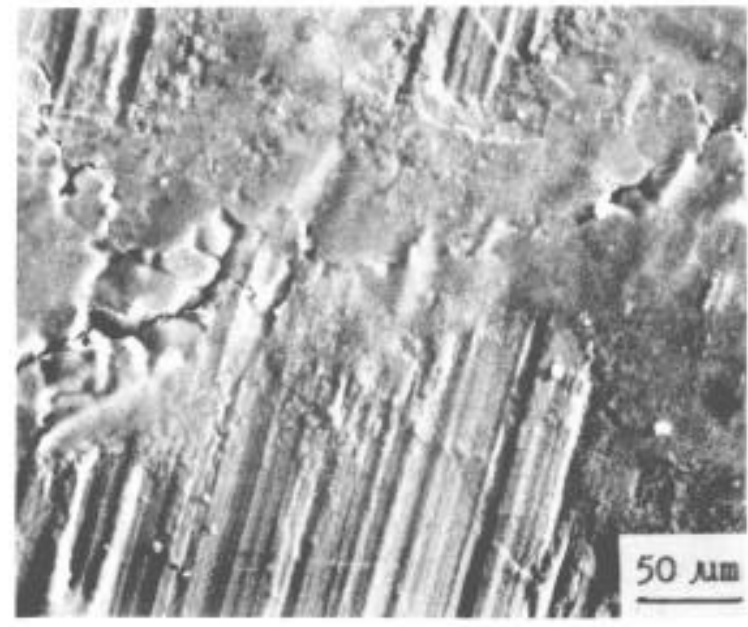

b)

Figure 6 -- Cracking and self recovery of crack at HAZ a) $\mathrm{K} 5$, b) $\mathrm{K} 5 \mathrm{H}$.

zone of Hf-rich melts in Fig.3. This proved relationship between formation of $\mathrm{HfO}_{2}$ and $\mathrm{Hf}-\mathrm{rich}$ melts.

\section{Discussion of Results}

In specimens of isothermal solidification and quenching at $1250^{\circ} \mathrm{C}$, dendrites of primary $\gamma$ are enveloped by $\mathrm{Hf}-\mathrm{rich}$ eutectic nets. It is predicted that skeleton of dendrites is brazed by Hf-rich melts. The idea using the melts as brazing material originates from the fact mentioned above. Later results have demostrated that $\mathrm{Hf}-\mathrm{rich}$ melts can really braze cast nickel base superalloy.

$\mathrm{Ni}_{5} \mathrm{Hf}$ is a unhelpful phase in superalloy, although it is not brittle. The target is to eliminate the phase from lapping zone. Fortunately, $\mathrm{Ni}_{5} \mathrm{Hf}$ is very unstable. Our work has revealed (6) that Nis HE can be removed by means of $1150^{\circ} \mathrm{C} / 8 \mathrm{~h}$ treatment in two ways: the reaction of $\mathrm{Ni}{ }_{5} \mathrm{Hf}+\gamma(\mathrm{C}) \rightarrow$ $M C_{(2)}+\gamma$ and the solid solution of NisHf into $\gamma^{\prime}$. In this paper the above results was proved further. Up to now, we both apply the low melting point characteristic of $\mathrm{Ni}$ Hf to brazing and obtain optimum microstructure of lapping. The benefit of this method is to avoid the troubles that Ni-Cr-Si-B brazing material brings large amount of Si, B and forms brittle phases in lapping zone.

The skin effect of Hf-rich melts is a practical phenomenon of physical metallurgy. During solidification of weld bead, the effect plays benefical role in self-brazing and makes existing solidification cracks healed. The fact that weld crack in Hf-containing alloy obviously reduces is related to the characteristic of Hf-rich melts. On the other hand, skin effect would bring disadvantageous influence on inverstment castings. Hf-rich skin liquid film having high activity contacts with shell mold and forms $\mathrm{HfO}_{2}$. High density $\mathrm{HfO}_{2}$ may be a trouble for using revert material, therefore the layer of $\mathrm{HfO}_{2}$ must be removed by grinding or blast-sanding. As revert material is remelted, residual $\mathrm{HfO}_{2}$ can be filter out through ceramic foam filters. 


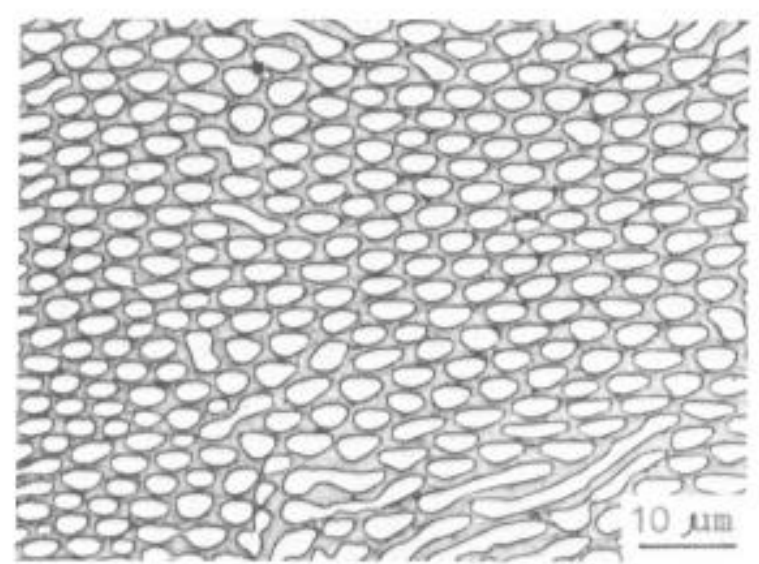

Figure 7 -- Microstructure of Hf-rich brazing material.

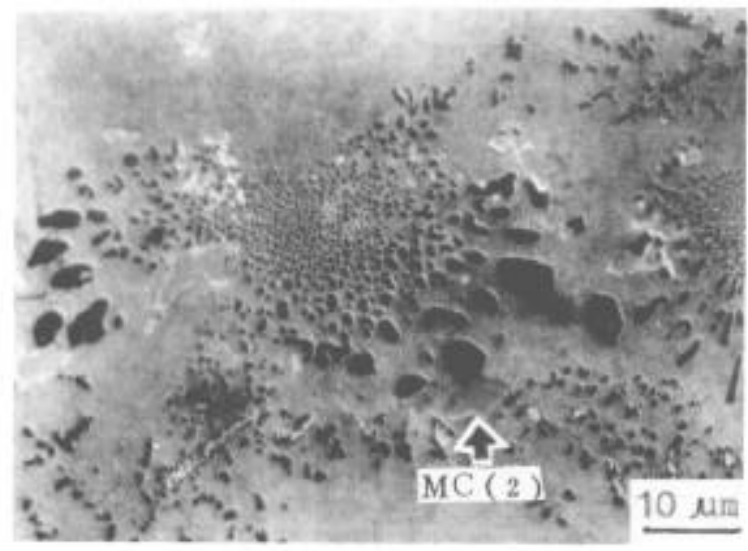

a)

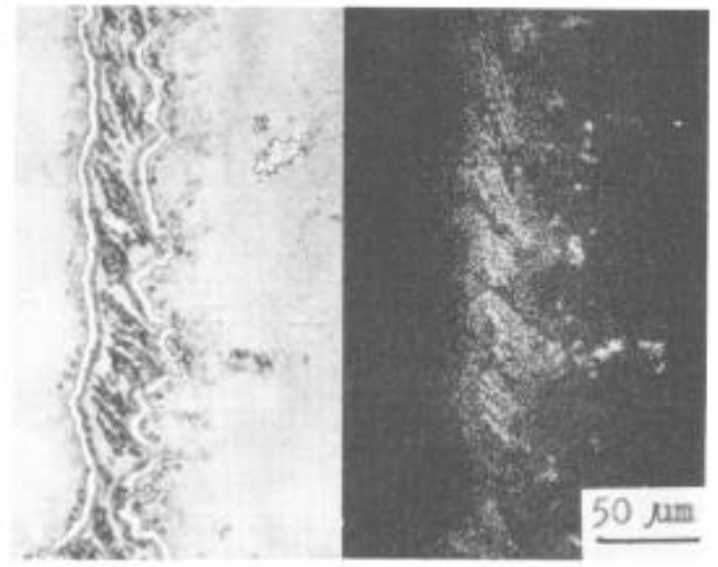

Figure 8 -- Microstructure of lapping zone and Hf profile.

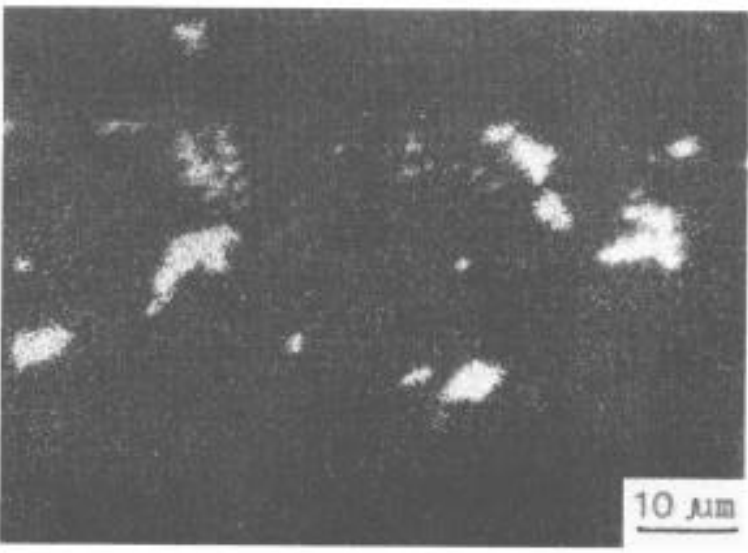

b)

Figure $9-M_{2}$, carbide and eutectic $\gamma+\gamma$ ' formed by diffusion treatment, a) morphology and b) Hf distribution.

\section{Conclusions}

1. Hf-rich melts have a skin effect when Hf-containing cast nickel-base superalloys melt or solidify at temperature range $1250-1290^{\circ} \mathrm{C}$. The melts flow out from interdendritic capillary filled by molten liquid and have superior fluidity. Hf content in skin liquid is four times more than its average content in the alloy.

2. The interdendritic liquid maintains improved interconnection before eutectic $\gamma^{\prime}$ forms and liquid volume percent necessary for keeping the interconnection is about $7 \mathrm{vol} \%$ at least. Moreover, Hf-rich skin melts have the capability of self brazing and the recovery effect on cracks. These are rea- 


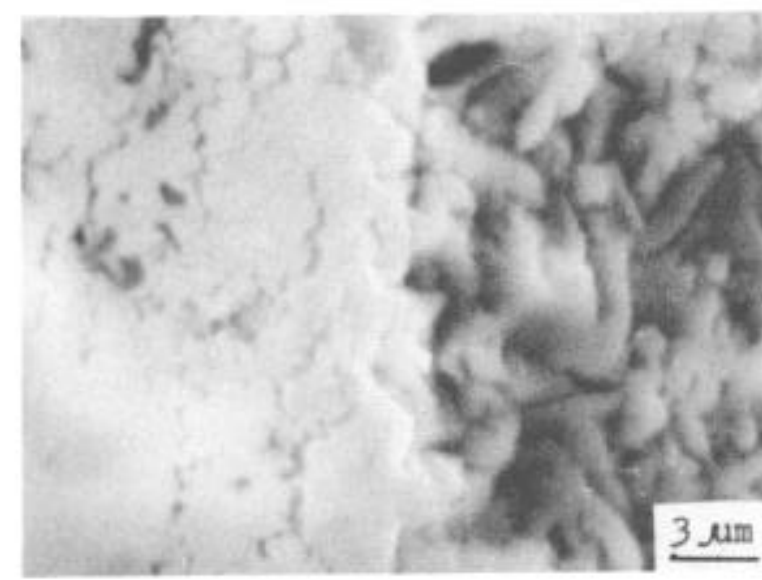

a)

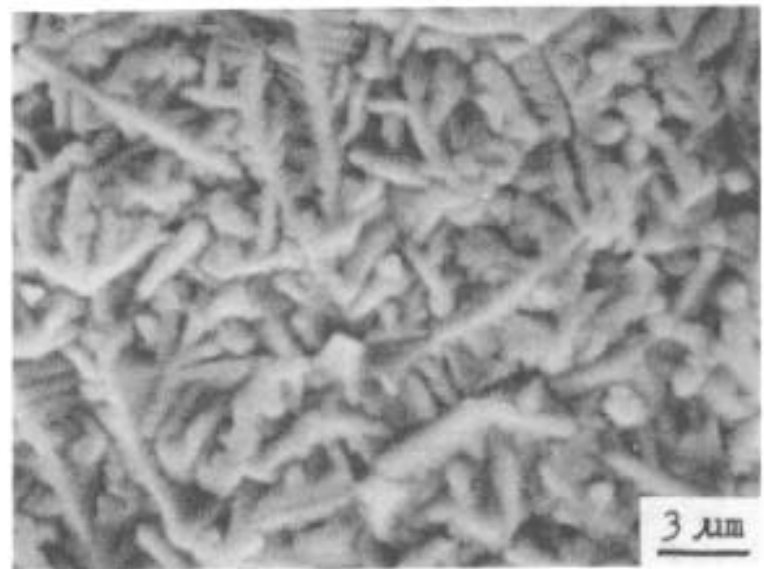

b)

Figure 10 -- Morphology of $\mathrm{HfO}_{2}$ for alloy $\mathrm{K} 3 \mathrm{H}^{*}$ a) local polishing and b) evaporating gold at surface.

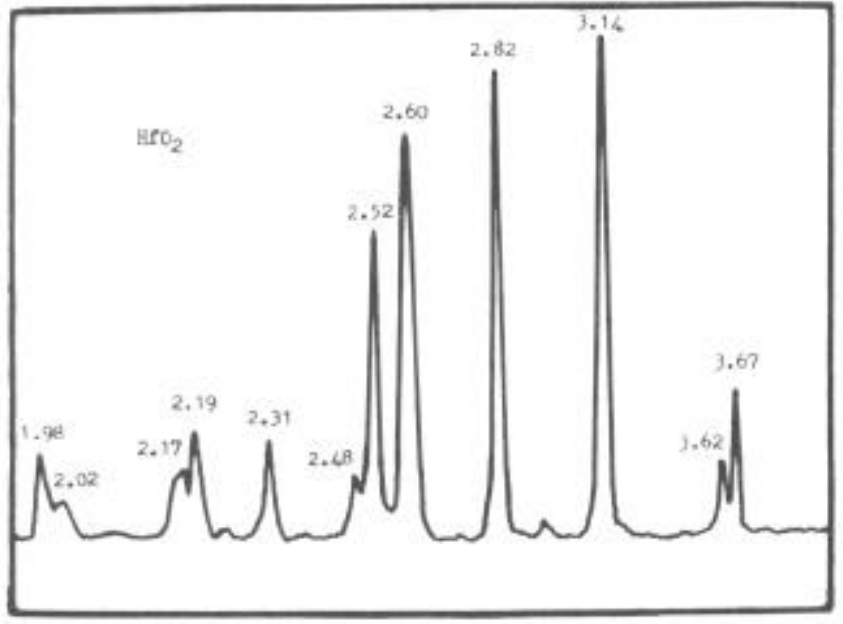

Figure 12 - $X$-ray diffraction diagram of $\mathrm{HfO}_{2}$ for $\mathrm{K} 3 \mathrm{H}$.

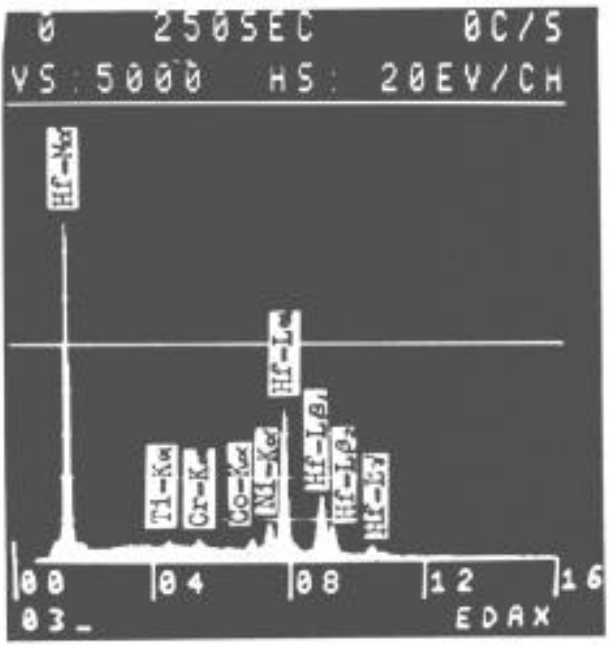

Figure 11 -- EDAX result of $\mathrm{HfO}_{2}$ for $\mathrm{K} 3 \mathrm{H}$.

sons that Hf-containing superalloys show low sensitivity to cast or weld cracking.

3. Hf-rich melts as a brazing material have shown advantages of low brittleness and reasonable lapping microstructure.

4. Skin liquid can react with shell mold and form a layer of $\mathrm{HfO}_{2}$.

\section{References}

1. J. M. Dah1, W. F. Danesi, and R. G. Dunn, "The Partitioning of Refractory Metal Elements in Hafnium-Modified Cast Nickel-Base Superalloys ", Met- 
allurgical Transactions, 4 (4) (1973), 1087-1096.

2. D. N. Duhl, and C. P. Sullivan, "Some Effect of Hafnium Additions on the Mechanical Properties of a Columnar-Grained Nickel-Base Superalloy", Journal of Metals 23 (7) (1971), 38-40.

3. R. Sellamuthu, and A. F. Giamei, "Measurement of Segregation and Distribution Coefficients in MAR-M200 and Hafnium-Modified MAR-M200 Superalloys ", Metallurgical Transactions A , 17A (3) (1986), 419-428.

4. R. Sellamuthu, H. D. Brody, and A. F. Giamei, "Effect of Fluid Flow and Hafnium Content on Macrosegregation in the Directional Solidification of Nickel Base Superalloys ", Metallurgical Transactions B, 17B (6) (1986) , 347-356.

5. Zheng Yunrong, "Behaviour of Hf in Solidification of Cast Ni-Base Superalloys ", Acta Metallurgical Sinica, 22 (2) (1986), A119-A124.

6. Zheng Yunrong, Wang Luobau and Li Chenggong, "Influence of Carbon Content and Solidification Condition on Incipient Melting of DS Superalloy Mar-M20O + 2Hf ", (Paper presented at the First ASM Europe Technical Conference, Paris, 7-9 September 1987). 